PNL-2530

UC-60

\title{
Gust-Rise Exceedance Statistics for Wind Turbine Design
}
C. H. Huang
G. H. Fichtl

July 1979

Prepared for the U.S. Department of Energy under Contract EY-76-C-06-1830

Pacific Northwest Laboratory Operated for the U.S. Department of Energy by Battelle Memorial Institute 


\title{
NOTICE
}

This report was prepared as an account of work sponsored by the United States Covernment. Neither the United States nor the Department of Energy, nor any of their employees, nor any of their contractors, subcontractors, or their employees, makes any warranty, express or implied, or assumes any legal liability or responsibility for the accuracy, completeness or usefulness of any information, apparatus, product or process disclosed, or represents that its use would not infringe privately owned rights.

The views, opinions and conclusions contained in this report are those of the contractor and do not necessarily represent those of the United States Government or the United States Department of Energy.

\author{
PACIFIC NORTHWEST LABORATORY \\ operated by \\ BATTELLE \\ for the \\ UNITED STATES DEPARTMENT OF ENERGY \\ Under Contract EY-76-C-06-1830
}

\author{
Printed in the United States of America \\ Available from \\ National Technical Information Service \\ United States Department of Commerce \\ 5285 Port Royal Road \\ Springfield, Virginia 22151 \\ Price: Printed Copy \$__ ; Microfiche $\$ 3.00$ \\ $\begin{array}{cc}\text { NTIS } \\ \text { - Pages } & \text { Selling Price }\end{array}$ \\ $001-025 \quad \$ 4.00$ \\ $026-050 \quad \$ 4.50$ \\ $051-075 \quad \$ 5.25$ \\ 076-100 $\quad 56.00$ \\ $101-125 \quad \mathbf{S 6 . 5 0}$ \\ $\begin{array}{ll}126-150 & \mathbf{5 7} .25\end{array}$ \\ $151-175 \quad \$ 8.00$ \\ $176.200 \quad 59.00$ \\ $201.225 \quad \$ 9.25$ \\ $226-250 \quad \$ 9.50$ \\ $251-275 \quad \$ 10.75$ \\ $276-300 \quad \$ 11.00$
}


PNL-2530

UC-60

\section{1}

GUST-RISE EXCEEDANCE STATISTICS

FOR WIND TURBINE DESIGN

C. H. Huang

G. H. Fichtl(a)

Ju7y 1979

Prepared for the U.S. Department of Energy under Contract EY-76-C-06-1830

PACIFIC NORTHWEST LABORATORY

Richland, Washington 99352

\footnotetext{
(a) Consultant 3706 College Park Circle Huntsville, AL 35805
} 
$\bullet$

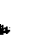

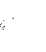<smiles>[3H]</smiles> 


\section{ACKNOWLEDGMENTS}

The authors would like to thank Drs. W. C. Cliff, L. L. Wendell, and C. E. Elderkin for their advice and review of the manuscript. We would also like to thank G. P. Tennyson of the Department of Energy (DOE) Wind Systems Branch (WSB) for his guidance. 


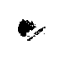

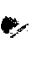




\section{SUMMARY}

When designing a wind machine, the number of large amplitude gusts for the design-life exposure of a wind machine should be estimated, because velocity change controls the acceleration rate of a rotor. Since the record length of data is insufficient, the theoretical study of gust rise may shed some light on the empirical formulation in which some important parameters may have been ignored.

Ficht ${ }^{(a)}$ developed an equation based on Rice's theory (1944, 1945), which estimates the total number of crossings with positive slope per unit of time that exceeds a prescribed level of velocity change. This paper discusses the analytical representation of Fichtl's formulation and presents useful results of the velocity change for the design life of a wind energy conversion system (WECS).

With a lag time of $10 \mathrm{sec}$ and an hourly mean longitudinal wind velocity of $10 \mathrm{~m} / \mathrm{sec}$, the magnitude of velocity change for $1-\mathrm{hr}$ recurrence is $6.5 \mathrm{~m} / \mathrm{sec}$ for a large wind machine; the magnitude of velocity change for 30-yr recurrence is larger than I-hr recurrence by a factor of about six. The magnitude of velocity change is substantially reduced, when the cutout velocity is incorporated into the calculation. For a given level of velocity change, the number of gust rises per unit of time also varies with the nondimensional parameter.

(a) G. H. Ficht1, "Technique for Calculating Wind-Speed Changes in the Atmospheric Boundary Layer for WECS Design." (Draft) 



\section{CONTENTS}

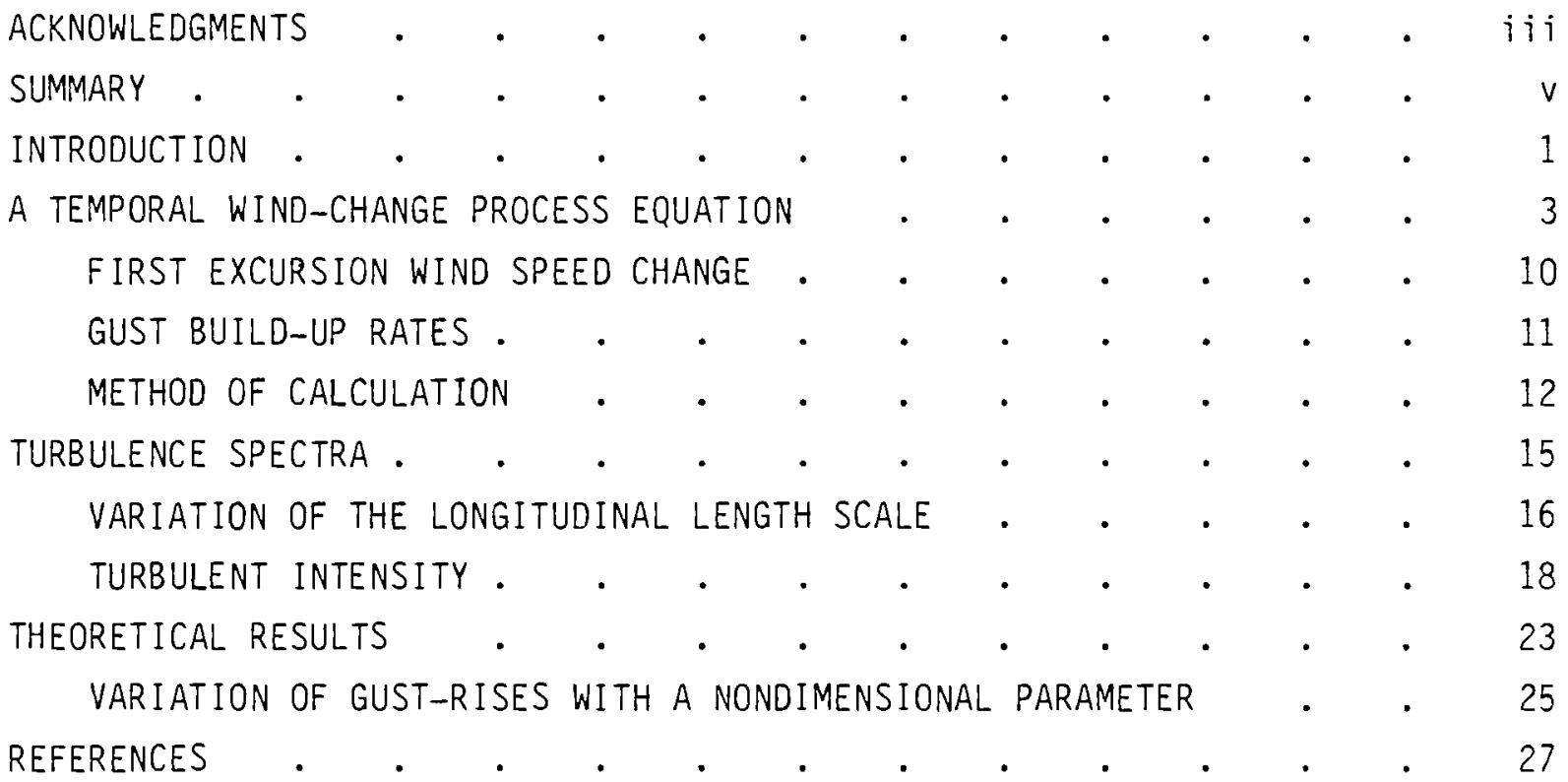




\section{FIGURES}

1 Realization of Velocity Change, $\Delta u$. $\quad . \quad$. $\quad . \quad$. $\quad . \quad$. $\quad . \quad 11$

2 Relationship Between the Temporary Velocity Changes and the Total Number of Crossings

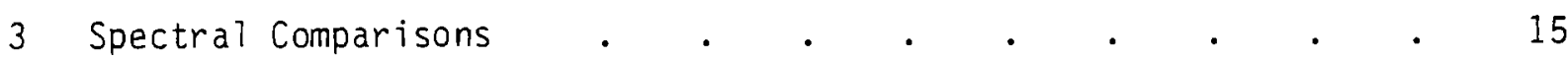

4 Longitudinal-Length-Scale Comparisons . . . . . . . . . 17

5 Variation of $\mathrm{C}$ and $1 / \mathrm{n}$ with Roughness Length . . . . . 18

6 Variation of Turbulence Intensity with Height and Surface Roughness

\section{TABLES}

1 Definition of Main Terrain Types . . . . . . . . . . 21

2 Velocity Change for $1-\mathrm{hr}$ Recurrence, $\mathrm{m} / \mathrm{sec} \quad$. . . . . . 23

3 Velocity Change for 30-yr Recurrence, $\mathrm{m} / \mathrm{sec}$. . . . . . . 24

4 Velocity Change for $30-y r$ Recurrence with Cutout Speed of
$25 \mathrm{~m} / \mathrm{sec}$.
. 


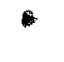

:

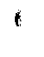




\section{INTRODUCTION}

In designing a wind machine as in conducting strength-and-fatigue analyses, the velocity changes over a certain lag time should be known, because the magnitude of velocity changes controls the acceleration rate of a rotor in a wind machine. The theoretical study of gust rise may shed some light on the formulation for general sites and may indicate some important parameters that have been ignored in the empirical formulation. Generally, field data are inadequate and the period for data collection is insufficient to make a definite conclusion on gust rise.

Ficht $\rceil^{(a)}$ developed an equation, based on Rice's theory (1944, 1945), for estimating the total number of crossings with positive slope per unit of time that exceeds a prescribed level of velocity change. This paper is concerned with the analytical representation of Fichtl's formulation and presents a method for obtaining useful results of the velocity change for the design life of a wind energy conversion system (WECS). The characteristics of turbulence spectra and the variability of length scale, turbulence intensity, and surface roughness that are needed for computing the total number of gust rises from the formula are also described briefly in this paper.

(a) G. H. Ficht1, "Technique for Calculating Wind-Speed Changes in the Atmospheric Boundary Layer for WECS Design." (Draft) 
$\bullet$

.<smiles></smiles> 


\section{A TEMPORAL WIND-CHANGE PROCESS EQUATION}

Fichtl ${ }^{(a)}$ derived an equation for the temporal wind-change process, based on Rice's theory $(1944,1945)$. In Fichtl's formulation, if the total number of crossings with positive slope per unit of time over the expected life of a wind machine is assumed known, then the magnitude of the velocity change over lag time $(\tau)$ can be determined. According to Rice's theory, the average number of temporal wind changes with positive slope per unit of time, which exceeds a prescribed value of velocity change $(\Delta u)$, may be expressed as:

$$
N(\Delta u)=N_{0} e^{-\frac{(\Delta u)^{2}}{2 \sigma^{2}}}
$$

where

- $\sigma_{\Delta u}=$ the standard deviation of velocity change $(\Delta u)$ because of turbulence gusts

- $\quad \mathrm{N}_{0}=$ the expected number of zero crossings with positive slope per unit of time because of wind change

- $\quad N_{0}$ is given by:

$$
N_{0}^{2}=\frac{1}{(2 \pi)^{2}} \frac{\int_{-\infty}^{\infty} \omega^{2} \phi \Delta(\omega) d \omega}{\int_{-\infty}^{\infty} \phi_{\Delta u}(\omega) d \omega}
$$

(a) G.H.Ficht1, "Technique for Calculating Wind-Speed Changes in the Atmospheric Boundary Layer for WECS Design." (Draft) 
where

- $\omega=$ the angular frequency in units of radian per unit of time

- $\phi_{\Delta u}=$ the spectra of $\Delta u$ in frequency domain as given by:

$$
\begin{gathered}
\phi_{\Delta u}(\omega, z, \tau)=2 \phi_{u}(\omega)(1-\cos \omega \tau) \\
=\frac{2}{\bar{u}} \frac{\sigma_{u}^{2} \cdot L_{u}}{\pi} \cdot \frac{1-\cos \omega \tau}{1+\left(\frac{L_{u} \omega}{\bar{u}(z)}\right)} 2
\end{gathered}
$$

where

- $z$ = the height above the ground

- $\bar{u}=$ hourly longitudinal wind velocity

- $\sigma_{u}=$ the standard deviation of longitudinal velocity

- $L_{u}=$ the integral scale length.

Equation (3) was obtained through the use of the Dryden spectral density function $\left[\phi_{u}(x)\right]$ for the longitudinal component of turbulence:

$$
\phi_{u}(x)=\frac{\sigma_{u}^{2} L_{u}}{\pi} \cdot \frac{1}{1+\left(L_{u} k\right)^{2}}
$$

Substituting Equation (3) into Equation (2), the following equation is obtained.

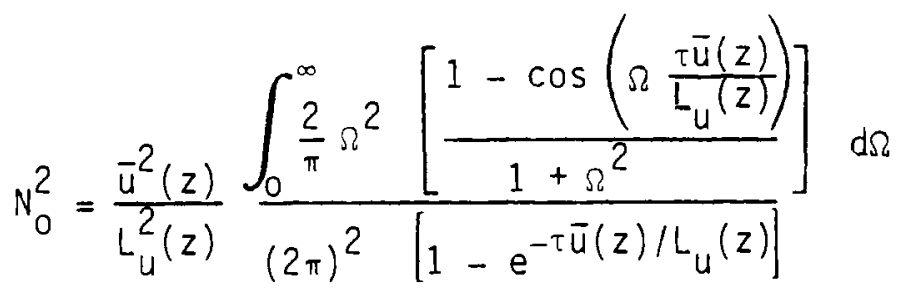


where

$$
\Omega(z)=\frac{L_{u}(z) \omega}{\bar{u}(z)}
$$

Introducing the log-law wind profile into Equation (5) results in:

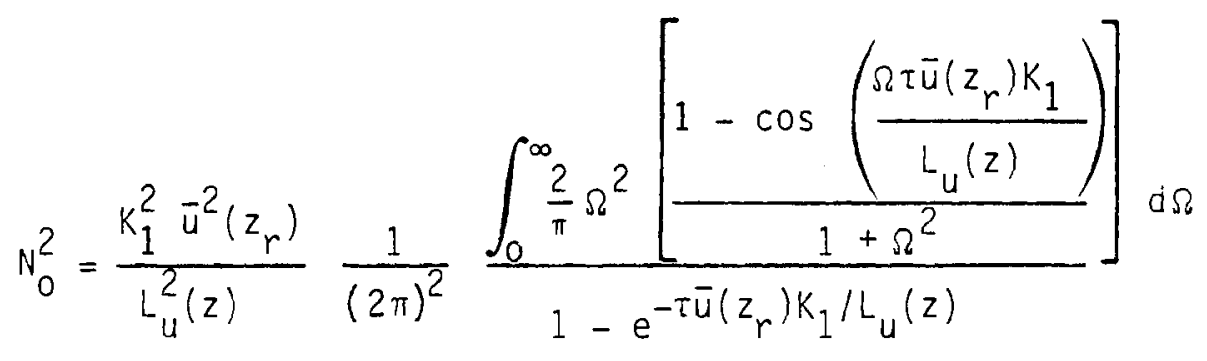

where

$$
k_{1}=\frac{\bar{u}(z)}{\bar{u}\left(z_{r}\right)}=\frac{\ln \left(\frac{z}{z_{0}}\right)-\psi\left(\frac{z}{L}\right)}{\ln \left(\frac{z_{r}}{z_{0}}\right)-\psi\left(\frac{z_{r}}{L}\right)}
$$

and for neutral conditions, $\quad \psi\left(\frac{Z}{L}\right)=0$

where

- $\bar{u}\left(z_{r}\right)=$ the wind speed at a reference height $\left(z_{r}\right)$

- $\psi=$ the correction term for the wind speed as a result of thermally stratified flow.

In Equation (1), the standard deviation $\left(\sigma_{\Delta u}\right)$, which depends on the standard deviation $\left(\sigma_{u}\right)$, must be known. However, since $\sigma_{u}$ is usually not known, it is expressed as a function of a known quantity. In the following, a relationship between $\sigma_{u}$ and the hourly mean longitudinal wind velocity $(\bar{u})$ is derived. 
According to the similarity theory, the ratio of $\sigma_{u} / u_{*}$ is a universal function of the Monin-Obukhov stability parameter $2 / L$ and $c a n$ be expressed as:

$$
\frac{\sigma_{u}}{u_{\star}}=F\left(\frac{z}{L}\right)
$$

where

- $F\left(\frac{2}{L}\right)=$ a universal function

- $u_{\star}=$ the friction velocity.

Under neutral conditions, the function $(F)$ is equal to 2.5 ; i.e., $F_{u}(0)=2.5$.

The wind profile follows the log law as:

$$
\bar{u}=\frac{u_{\star}}{k}\left[\ln \left(\frac{z}{z_{0}}\right)-\psi\left(\frac{z}{L}\right)\right]
$$

where

- $z_{0}=$ the surface roughness

- $k=$ the von Karman constant, 0.4

- $z=$ the hub height above the ground.

Therefore, the standard deviation $\left(\sigma_{u}\right)$ is related to the hourly mean longitudinal wind velocity $(\bar{u})$ by:

$$
\sigma_{u}=k_{2} \bar{u}\left(z_{r}\right)
$$

where

$$
k_{2}=\frac{F\left(\frac{z}{L}\right) k}{2 n \frac{z_{r}}{z_{0}}-\psi\left(\frac{z_{r}}{L_{0}}\right)}
$$


From the definition of $\sigma_{\Delta u}$ and by using Equation (9), the standard deviation $\sigma_{\Delta u}$ is:

$$
\sigma_{\Delta u}^{2}=2 k_{2}^{2} \vec{u}^{2}\left(z_{r}\right) \quad\left[1-e^{-k_{1} \bar{u}\left(z_{r}\right) \tau / L_{u}(z)}\right]
$$

where

- $\bar{u}\left(z_{r}\right)$ is the hourly mean longitudinal wind velocity at the reference height.

To obtain the climatological exceedance rate of $\Delta u$, the total number of crossings of $\Delta u$ must be found. This may be done by introducing the probability density function of hourly mean longitudinal wind velocity as follows:

$$
N(\Delta u)=\int_{0}^{\infty} N_{0} e^{-\frac{\Delta u^{2}}{2 \sigma^{2}} \Delta u} p\left[\bar{u}\left(z_{r}\right)\right] d \bar{u}\left(z_{r}\right)
$$

The Weibull distribution and the Rayleigh distribution for hourly mean longitudinal wind velocity $[P(u)]$ are frequently used to fit the climatological mean wind distribution. Since the Rayleigh distribution of hourly mean longitudinal wind velocity is completely determined if the climatological hourly mean longitudinal wind velocity is known, the probability density function $p\left[u\left(z_{r}\right)\right]$ as in Equation (11) will be used as the Rayleigh distribution.

$$
\begin{aligned}
p\left[\bar{u}\left(z_{r}\right)\right] & =\frac{\bar{u}\left(z_{r}\right)}{\theta^{2}} e^{-\frac{\bar{u}^{2}\left(z_{r}\right)}{2 \theta^{2}}} \\
\theta & =\sqrt{\frac{2}{\pi}}\left\langle\bar{u}\left(z_{r}\right)\right\rangle
\end{aligned}
$$


where

- $\left\langle u\left(z_{r}\right)\right\rangle=$ the climatological ensemble average, i.e., the climatological mean longitudinal wind velocity such as the annual mean longitudinal wind velocity speed.

Substituting Equation (12) into Equation (11) results in:

$$
N(\Delta u)=\int_{0}^{\infty} N_{0} e^{-\frac{\Delta u^{2}}{2 \sigma^{2}}} \frac{\bar{u}}{\theta^{2}} e^{-\frac{\bar{u}^{2}\left(z_{r}\right)}{2 \theta^{2}}} d \bar{u}\left(z_{r}\right)
$$

For convenience, Equation (13) is expressed in nondimensional form as:

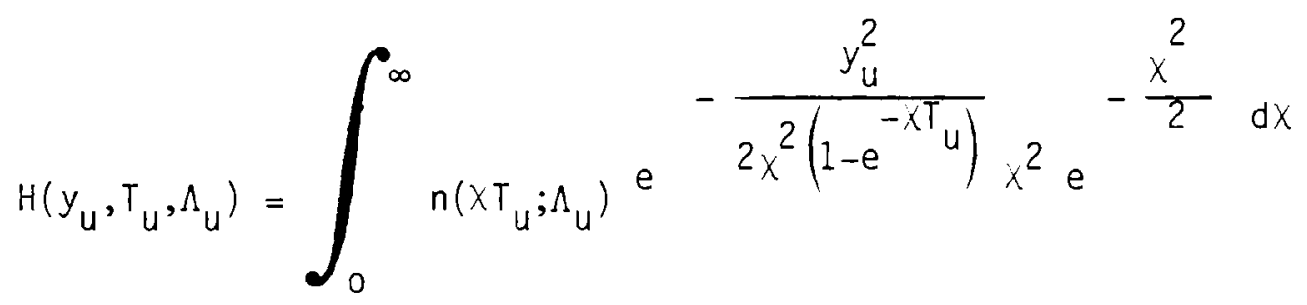

where

$$
\begin{aligned}
& x=\frac{\bar{u}\left(z_{r}\right)}{\theta} \\
& \Lambda_{u}=\frac{{ }^{\lambda} c}{L_{u}(z)} \\
& \tau=\text { the lag time for the velocity change }(\Delta u) \\
& H\left(y_{u}, T_{u}, \Lambda_{u}\right)=N(\Delta u) \frac{L_{u}(z)}{K_{1} \theta}=N(\Delta u) \frac{L_{u}(z) \ln \left(\frac{z_{r}}{z_{0}}\right)}{\theta \ln \left(\frac{z}{z_{0}}\right)}
\end{aligned}
$$




$$
\begin{aligned}
& y_{u}=\frac{\Delta u \text { en }\left(\frac{z_{r}}{z_{0}}\right)}{\sqrt{2}(2.5) k \theta} \\
& T_{u}=\frac{\tau \theta \ln \left(\frac{z}{z_{0}}\right)}{L_{u}(z) \ln \left(\frac{z_{r}}{z_{0}}\right)} \\
& n\left(x T_{u}\right)=\frac{1}{2 \pi}\left\{\int_{0}^{\infty}\left[\frac{\left.2 \Omega^{2} \frac{1-\cos \left(x T_{u} \Omega\right)}{1+\Omega^{2}}\right] d \Omega}{1-e^{-x T_{u}}}\right\}^{1 / 2}\right.
\end{aligned}
$$

where $n$ as defined in Equation (18) relates to the expected number of zero crossings as a result of wind change $\left(N_{0}\right)$.

The integral in Equation (18), which corresponds to that of Equation (2), diverges; this implies that an infinite number of zero crossings occur for velocity change $(\Delta u)$. The infinite number of crossings arises from high-frequency fluctuations. In reality, viscosity causes a sharper roll-off (at high frequencies) than normal atmospheric spectra would indicate; besides, any instrument's response to turbulence will filter out high-frequency fluctuations. As a result, the total number of zero crossings for $\Delta u$ remains finite. Therefore, a cutoff wavelength with the quantity $\lambda_{c}$ is introduced so that $N_{0}$ will remain bound. Based on the shortest gust wavelength to which an instrument responds, $\lambda_{C}$ was selected so that for wavelengths shorter than ${ }^{2} c$ negligible or no additional response is obtained. Because Equation (14) contains double integrals, it is time consuming to evaluate Equation (14); therefore, an analytical expression for Equation (18), which saves computational time, can be approximately written as: 


$$
n\left(X T_{u} ; \Lambda_{u}\right)=\frac{1}{2 \pi}\left\{\frac{\left.\frac{2}{\pi}\left[\int_{0}^{2 \pi / \Lambda_{u}}\left[\frac{\Omega^{2}}{1+\Omega^{2}}-\cos \left(x T_{u} \Omega\right)\right] d \Omega\right]+\int_{0}^{\infty} \frac{\cos \left(X T_{u} \Omega\right)}{1+\Omega^{2}} d \Omega\right)^{1 / 2}}{1-e^{-\chi \cdot T_{u}}}\right\}(19)
$$

Because the first term on the right-hand side of Equation (19) diverges, a cutoff wavelength $\left(\lambda_{c}\right)$ is introduced. Therefore, no cutoff wavelength is introduced into the second term on the right-hand side of Equation (19). Thus, Equation (19) can be analytically expressed as:

$n\left(x \cdot T_{u} ; \Lambda_{u}\right)=\frac{1}{2 \pi}\left\{-1+\frac{\frac{2}{\pi}\left[\Omega-\tan ^{-1} \Omega-\frac{1}{x \cdot T} \sin \left(x \cdot T_{u} \Omega\right)+1\right]}{1-e^{-x \cdot T_{u}}}\right\}^{1 / 2}$

The total number of crossings $(N)$ for the velocity change that exceeds a prescribed value of velocity change $(\Delta u)$ or vice versa can be calculated from Equation (14); once the climatological mean longitudinal wind velocity, the turbulence scale, and the dimension of the structure $\left(\lambda_{c}\right)$ are known. However, if the expected life of a structure is known, $N$ can be determined by using the Poisson equation. The velocity change $(\Delta u)$ for a lag time $(\tau)$ in seconds can be estimated from Equation (14). For example, suppose the expected life of a structure is $30 \mathrm{yr}$ and the risk is $63 \%$. In such a situation, the velocity change that exceeds a value of $\Delta u$ at least once in $30 \mathrm{yr}$ can be calculated using Equation (14).

\section{FIRST EXCURSION WIND-SPEED CHANGE}

A realization of velocity change $(\Delta u)$ is schematically shown in Figure 1. Time $\left(t_{1}\right)$ is associated with the first excursion of $\Delta u$, which exceeds a prescribed value of $(\Delta u)$ critical. The collection of the time of the first excursion is statistically distributed. A Poisson failure model $c a n$ be used to describe this statistical distribution; it can also be used to relate risk $(R)$ to the design life of a WECS, $\left(t_{0}\right.$ for $\left.t>t_{0}\right)$. According to the Poisson failure model, 


$$
R=1-e^{-N t_{0}}
$$

or

$$
N=\frac{\ln (1-R)}{t_{0}}
$$

where $N$ is the average rate of crossings of the velocity change $\Delta u$, which exceeds a prescribed value of $(\Delta u)$ critical. N can be calculated once risk and WECS life $\left(t_{0}\right)$ are known. By substituting $N$ and the specified values of $\tau, z_{0}, z, z_{r}, \theta, L(z)$, and $\Lambda_{u}$ into Equation (14), the velocity change ( $\Delta$ u) can be calculated.

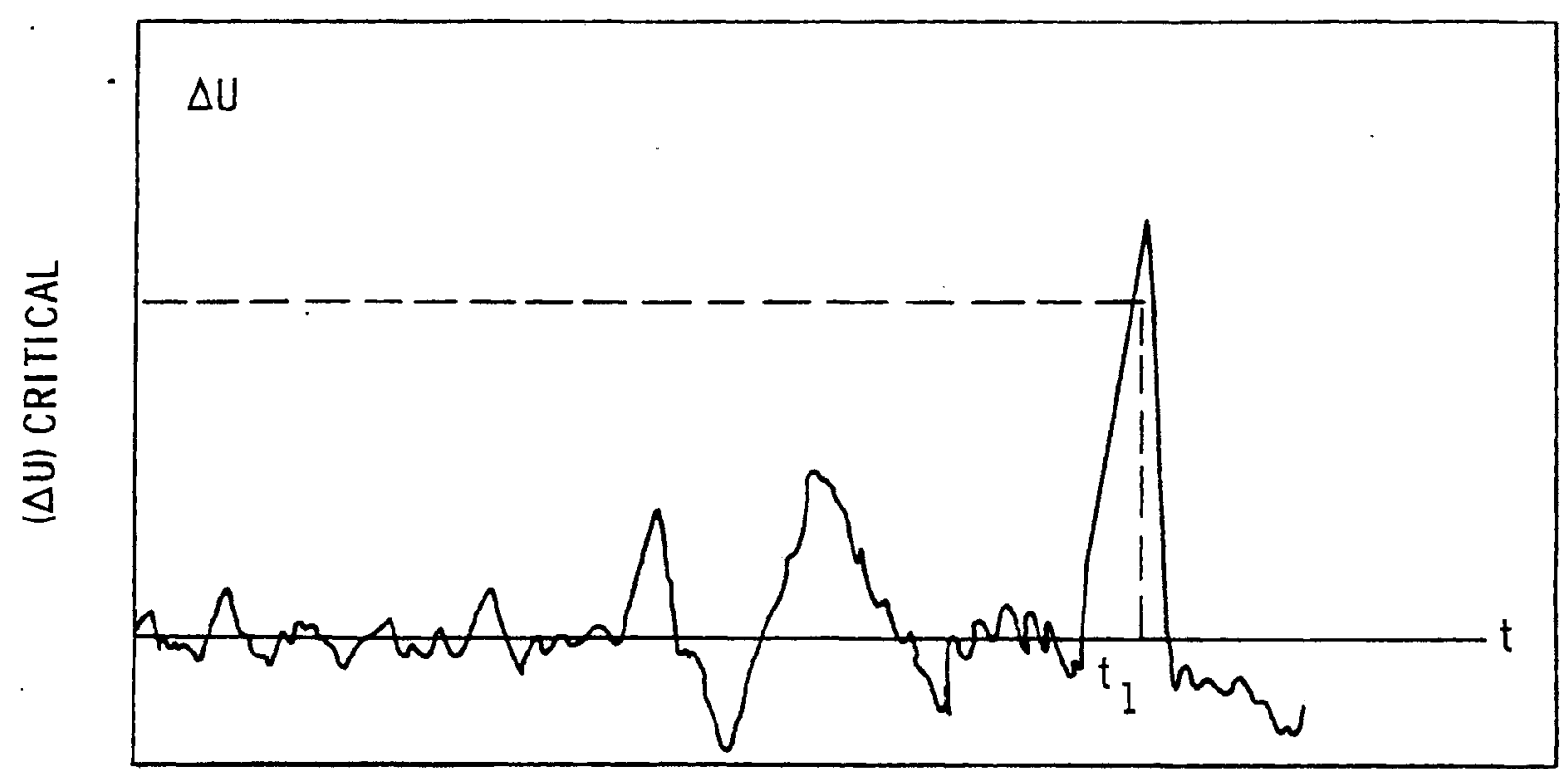

FIGURE 1. Realization of Velocity Change, su, with time, $t$

\section{GUST BUILD-UP RATES}

In the previous section, the rate of the total number of crossings ( $N$ ) for the velocity change exceeding $\Delta u$, including the climatological mean wind distribution, was discussed. In this subsection, the climatological mean wind distribution will not be considered; instead, the gust build-up rates as expressed directly in Equation (1) will be considered. 
By using the Poisson failure model, the following equation results:

$$
N(\Delta u)=N_{0} e^{-\frac{(\Delta u)^{2}}{2 \sigma_{\Delta u}^{2}}}
$$

Equation (23) yields the nondimensional velocity change as follows:

$$
\Delta U=\sqrt{2}\left(1-e^{-T}\right)^{1 / 2}\left[\ln \left(-\frac{T_{L} n_{0}}{\ln (1-R)}\right)\right]^{1 / 2}
$$

where

$$
\begin{aligned}
& \Delta U=\frac{\Delta u}{\sqrt{2} k_{2} \bar{u}_{r}} \\
& T=\frac{k_{1} \bar{u}_{r} \tau}{L_{u}} \\
& T_{L}=\frac{\vec{u}_{r} K_{1}}{L_{u} 2 \pi} t_{L} \\
& n_{0}=\frac{N_{0} L_{u} 2 \pi}{\bar{u}_{r} K_{1}}=\left\{-1+\frac{\frac{2}{\pi}\left[\Omega-\tan ^{-1} \Omega-\frac{1}{T} \sin (T \Omega)\right]+1}{1-e^{-T}}\right\}^{1 / 2}
\end{aligned}
$$

and $t_{L}$ is the time of exposure in the design wind condition.

METHOD OF CALCULATION

For convenience, Equation (1) for velocity change ( $\Delta u$ ) is rewritten as follows: 


$$
H\left(y_{u}, T_{u}, \Lambda_{u}\right)=\int_{0}^{\infty} n\left(X T_{u} ; \Lambda_{u}\right) e^{-\frac{y_{u}^{2}}{2 x^{2}\left(1-e^{-X T} u\right)}} x^{2} e^{-\frac{x^{2}}{2}} d x
$$

where

$n_{u}\left(X \cdot T_{u} ; \Lambda_{u}\right)=\frac{1}{2 \pi}\left\{-1+\frac{\frac{2}{\pi}\left[\Omega-\tan ^{-1} \Omega-\frac{1}{X \cdot T_{u}} \sin \left(X \cdot T_{u} \Omega\right)+1\right]}{1-e^{-X \cdot T_{u}}}\right\}^{1 / 2}$

With the specification of $\Delta u, \tau, z_{0}, z, z_{r}, \theta, L(z)$ and $\Lambda$, the integral in Equation (25) can be calculated by using Simpson's rule; thus, the values of $H$ or $N$ can be calculated for various values of $\tau, \Lambda_{u}$, and $\Delta u$. With the risk value for WECS and the diameter of a rotor specified, the relationship can be established between the velocity change ( $\Delta u$ ) exceeding a prescribed value of $\Delta u$ at least once in the design life of a WECS and the lag time $(\tau)$.

A plot of the total number of nondimensional gusts $(H)$ with amplitude exceeding a prescribed level of nondimensional velocity change $\left(y_{u}\right)$ for various lag times $(\tau)$ is shown in Figure 2. For a specified value of $H$ that can also be determined from Equation (21) and $\tau$, the nondimensional velocity change $\left(y_{u}\right)$ can be estimated for the life exposure of a WECS design (see Figure 2).

Knowledge of longitudinal spectra is needed to calculate the total number of gusts with amplitude exceeding the velocity change $(\Delta u)$. Therefore, the different turbulence spectra, the turbulence intensity and length scale that are needed to compute the turbulence spectra will be described briefly in the following sections. 


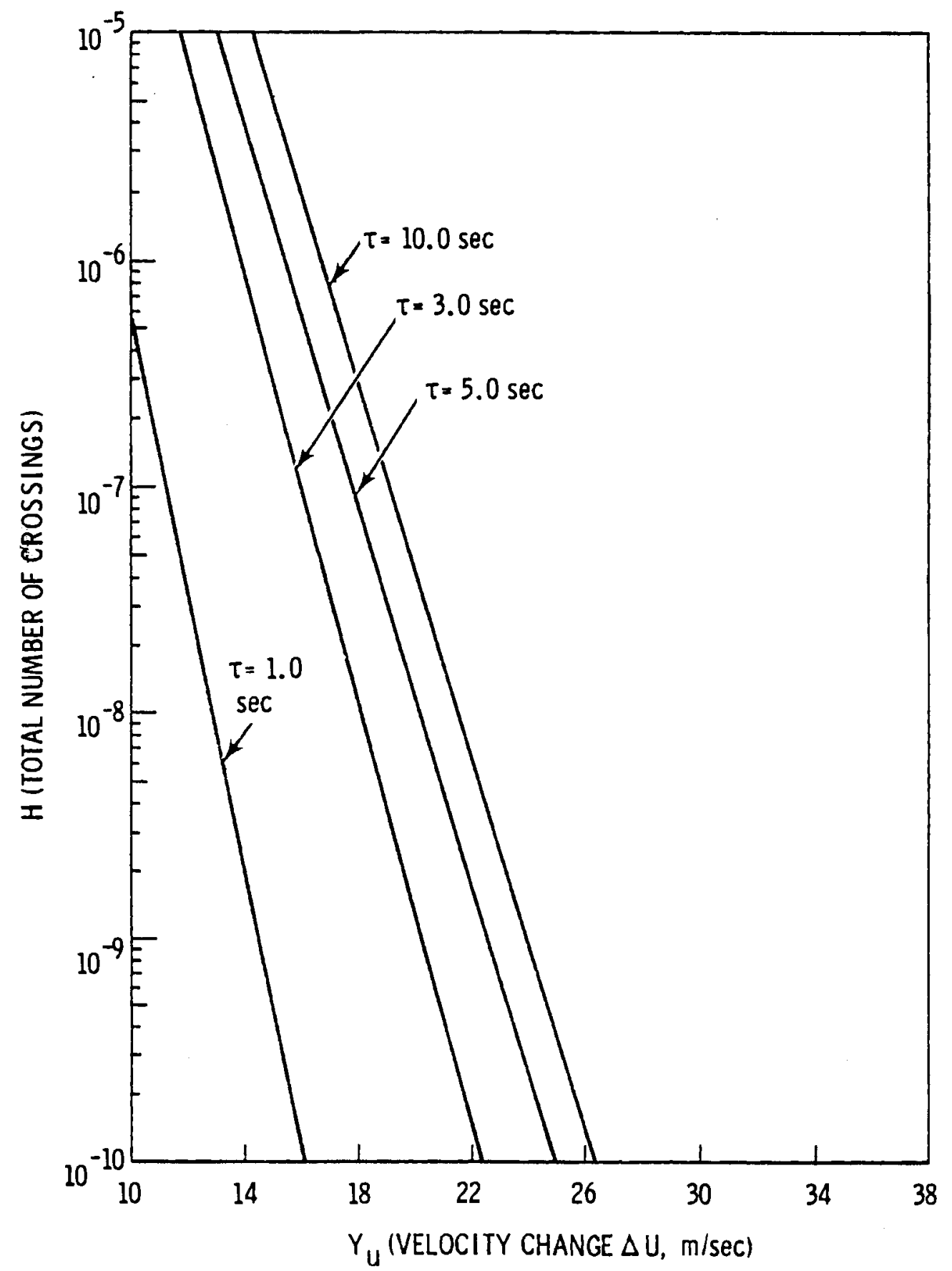

FIGURE 2. Relationship Between the Temporary Velocity Changes and the Total Number of Crossings 


\section{TURBULENCE SPECTRA}

Turbulence spectra such as Dryden's spectra and von Karman's spectra have been frequently applied to turbulence simulations and fatigue analyses in aerospace engineering. In order to understand the limitations of these spectra and to determine their range of applicability, these spectra and Kaimal's spectra were compared by plotting these spectra as shown in figure 3. Kaimal's spectra was obtained from the wind measurements for the surface boundary layer below $30 \mathrm{~m}$. The validity of Kaimal's spectra above $30 \mathrm{~m}$ is not yet known; however, the comparison of the stable case of Kaimal's spectra and von Karman's spectra indicates that these two spectra are similar. Since von Karman's spectra has been frequently applied to the layer above $30 \mathrm{~m}$ and since Kaimal's spectra is similar, Kaimal's spectra in

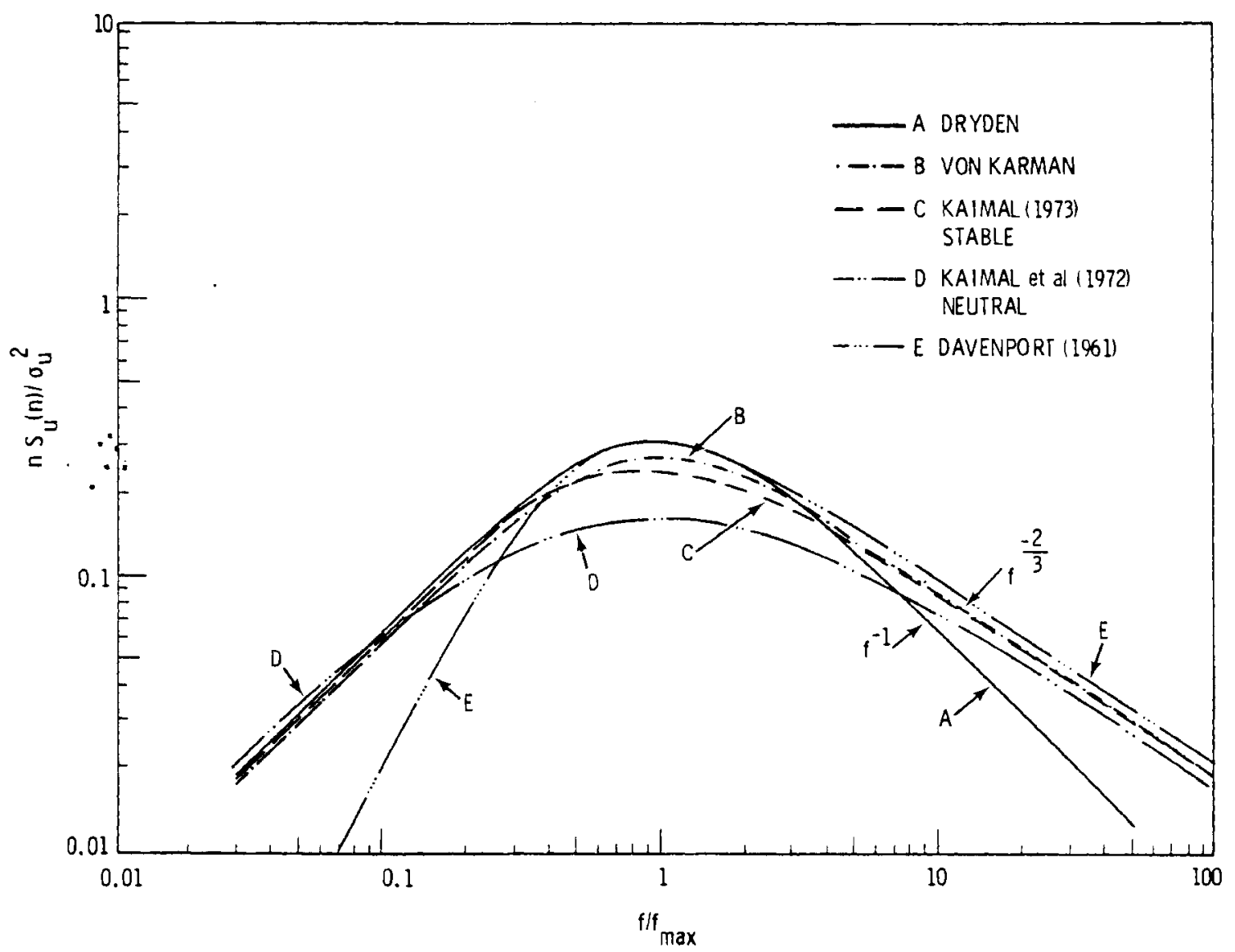

FIGURE 3. Spectral Comparisons 
the stable case may also be a good representation of the turbulence characteristics above the surface boundary layer. For neutral conditions, Kaimal's spectra departs significantly from von Karman's; therefore, the validity of these spectra above $30 \mathrm{~m}$ should be validated by wind data. The information on length scale and turbulence intensity needed in computing the turbulence spectra is described in the following subsections.

VARIATION OF THE LONGITUDINAL LENGTH SCALE

Variation of the longitudinal length scale has been investigated and many longitudinal-length-scale models have been proposed. Most researchers suggest that the longitudinal length scale increases with height as shown in Figure 4 (Barr, Gangsaas and Schaeffer 1974; Luers 1973; Teunissen 1970; Counihan 1975). Counihan (1975) suggested that the longitudinal length scale depends on the surface roughness and proposed a formula for the longitudinal length scale $\left(L_{u}\right)$ at $z=30 \mathrm{~m}$ :

$$
L_{u}=108\left(\frac{1}{z_{0}}\right)^{1 / 6}
$$

which indicates that longitudinal length scale decreases with increasing surface roughness. In order to take into account the influence of surface roughness in the longitudinal length scale, Counihan (1975) suggested that the longitudinal length scale be expressed as:

$$
L_{u}=c z^{\frac{1}{n}}
$$

where the parameters $c$ and $n$ vary with the surface roughness length $\left(z_{0}\right)$. Variations of these parameters with different terrain types are shown in Figure 5. Figure 5 also shows that the longitudinal length scale decreases with increasing surface roughness. For computational convenience, a regression fit for parameters, $c$ and $n$, based on the curves given by Counihan (1975) was obtained: 


$$
\begin{gathered}
c=\frac{25}{z_{0}^{0.4}} \\
\frac{1}{n}=-0.25\left(\ln z_{0}\right)^{2}+0.17 \ln z_{0}-0.8
\end{gathered}
$$

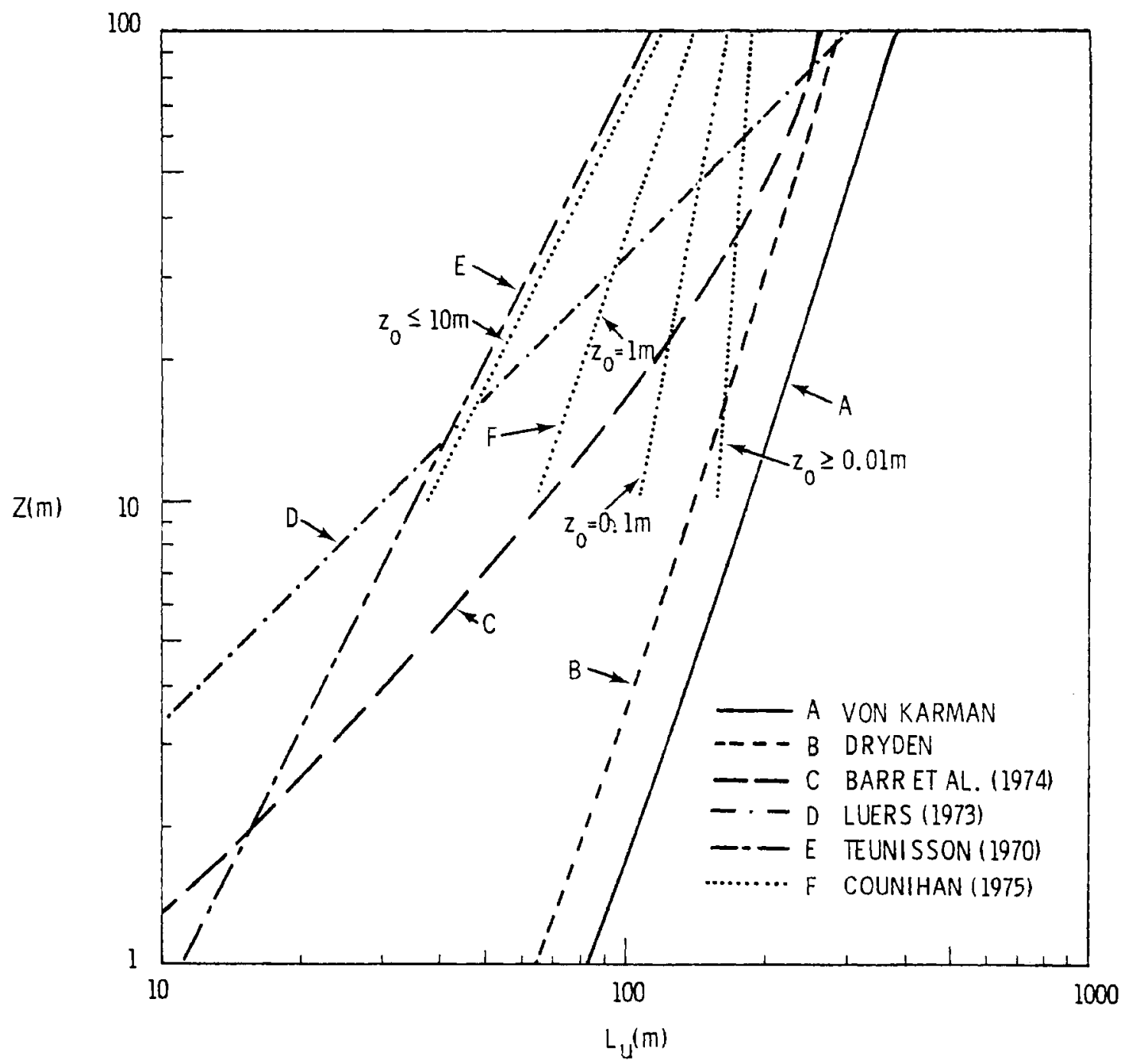

LONGITUDINAL LENGTH SCALE COMPARISONS

FIGURE 4. Longitudinal-Length-Scale Comparisons 


\section{TURBULENT INTENSITY}

If Monin-0bukhov similarity for the longitudinal turbulent fluctuations and the log-law wind profile are used, the turbulence intensity (see Equation 9) can be expressed as:

$$
\frac{\sigma_{u}}{\bar{u}}=k_{2}
$$

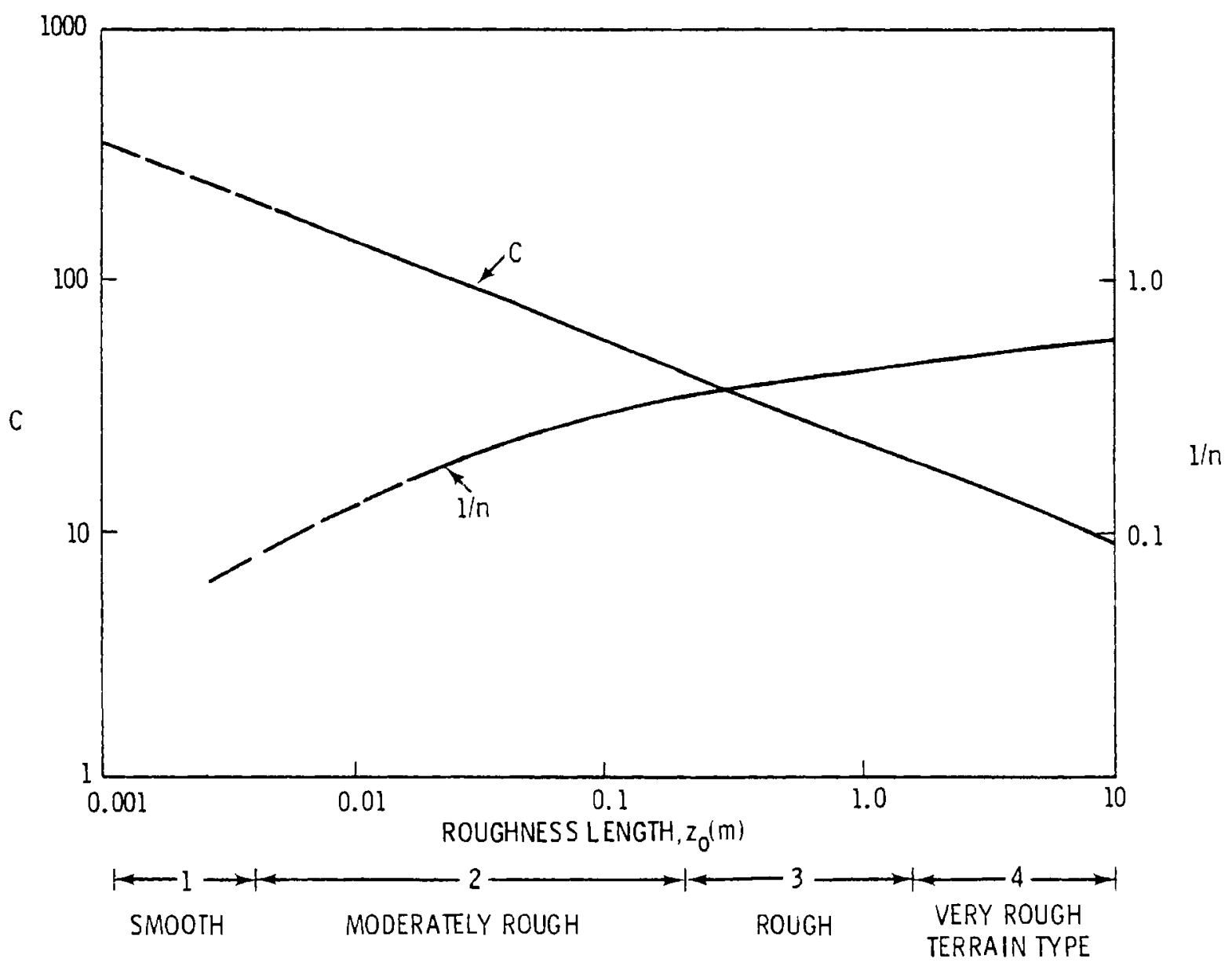

FIGURE 5. Variation of $\mathrm{C}$ and $1 / \mathrm{n}$ with Roughness Length 
where for neutral conditions,

$$
k_{2}=\frac{F\left(\frac{z}{L}\right) k}{\ln \frac{z}{z_{0}}-\psi\left(\frac{z}{L}\right)}=\frac{1}{\ln \frac{z}{z_{0}}}
$$

Equation (29) shows that the turbulent intensity depends on the atmospheric stability, surface-roughness length, and height. The data of turbulent intensity collected by Counihan (1975) and Shelland (1968) are plotted in Figure 6 . Figure 6 shows the variation of turbulent intensity with surfaceroughness length $z_{0}$. The turbulent intensity expressed in Equation (29) for various surface roughness and for the heights 10, 30, and $50 \mathrm{~m}$ under neutral conditions is also plotted in Figure 6 . Curve $A$ in Figure 6 is the regression fit of the experimental data proposed by Counihan (1975). For smaller surface-roughness lengths up to $z_{0}=0.1$, the curves $B$ and $C$ obtained from the similarity theory at heights of $z=10 \mathrm{~m}$ and $z=30 \mathrm{~m}$, respectively, fit the experimental data well; however, for greater surface roughness, curve $D$, based on the similarity theory, is a good fit of experimental data up to the surface-roughness length of $z_{0}=1.0 \mathrm{~m}$. Beyond $z_{0}=1.0$, very little experimental data are available.

Further work on the measurements of turbulence intensity over high mountains or very rough urban areas is needed. In this rougher type of terrain, the value of turbulent intensity is suggested to be 0.3 to 0.4 . The theoretical results and the experimental data, as shown in Figure 6 , indicate that the turbulence intensity increases with increasing surface roughness and decreases with height. The relationship between various types of terrain features and surface-roughness length is shown in Table 1 (Counihan 1975). 


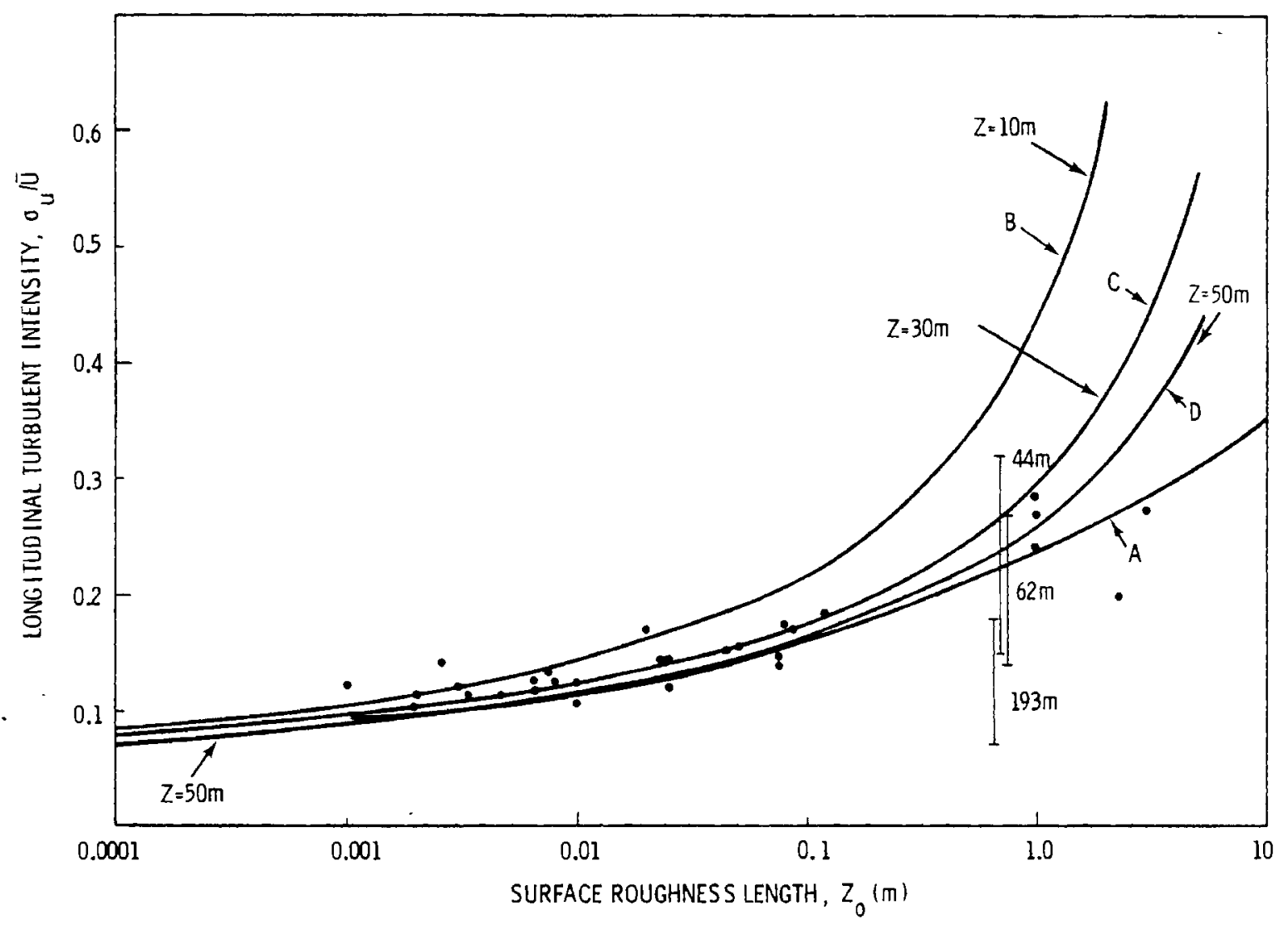

FIGURE 6. Roughness Variation of Turbulence Intensity with Height and Surface 
TABLE 1. Main Terrain Types and Surface Roughness Length

\begin{tabular}{|c|c|c|c|c|c|c|}
\hline \multirow{3}{*}{$\frac{\text { Quantity }}{z_{0} \mathrm{~cm}}$} & \multicolumn{6}{|c|}{ Terrain Types } \\
\hline & $\begin{array}{c}\text { SM00TH } \\
\text { Ice-Mud-Snow-Sea }\end{array}$ & $\begin{array}{l}\text { MODERATELY ROUGH } \\
\text { Grass-Crops-Rural }\end{array}$ & \multicolumn{3}{|c|}{$\begin{array}{c}\text { ROUGH } \\
\text { Woods-Woods-Suburbs }\end{array}$} & \multirow{2}{*}{$\begin{array}{c}\begin{array}{c}\text { VERY ROUGH } \\
\text { Urban }\end{array} \\
100-300-400\end{array}$} \\
\hline & $0.001-0.04-0.1-0.2$ & $0.1-3-7-20$ & 100 & - & 150 & \\
\hline$\overline{u^{\prime}} w^{\prime} / u_{0}^{2}$ & $0.0004-0.006-0.001$ & $0.0014-0.0020-0.0040$ & & - & & - \\
\hline $1 / a$ & $0.08-0.11-0.12$ & $0.13-0.143-0.16$ & 0.20 & - & 0.23 & $0.25-0.40$ \\
\hline$\left(\sqrt{\bar{u}^{\prime 2}} / \bar{u}\right) 0 \leq z(m) \leq 30$ & 0.12 & 0.20 & - & 0.20 & - & $0.30-0.48$ \\
\hline
\end{tabular}



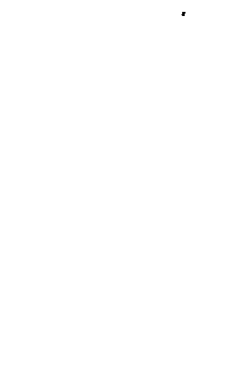


\section{THEORETICAL RESULTS}

The magnitude of velocity change of 1-hr recurrence computed from Equation (24) for three different types of WECS and various lag times are shown in Table 2. In obtaining the results in Table 2, the hub height of a WECS was at $50 \mathrm{~m}$ and the value of risk at 0.63 . For one-dimensional turbulence, the effect of windmill size on the velocity change is relatively small as shown in Table 2. With a lag time of $10 \mathrm{sec}$ and mean wind speed of $10 \mathrm{~m} / \mathrm{sec}$, the magnitude of velocity change is $6.46 \mathrm{~m} / \mathrm{sec}$ for a large wind machine.

TABLE 2. Velocity Change for $1-h r$ Recurrence, $\mathrm{m} / \mathrm{sec}$

Diameter of Wind Turbine, $m$

\begin{tabular}{|c|c|c|c|}
\hline$\tau, \sec$ & Small, $1 \mathrm{~m}$ & Medium, $10 \mathrm{~m}$ & Large, $60 \mathrm{~m}$ \\
\hline 0.05 & $0.8879(a)$ & 0.6776 & 0.5785 \\
\hline 0.1 & 1.2257 & 0.9925 & 0.777 \\
\hline 0.3 & 2.0324 & 1.7930 & 1.3072 \\
\hline 0.5 & 2.5621 & 0.3252 & 1.7238 \\
\hline 1.0 & 3.4861 & 3.1453 & 2.5288 \\
\hline 3.0 & 5.5156 & 4.9251 & 4.4069 \\
\hline 5.0 & 6.6701 & 5.9260 & 5.3234 \\
\hline 10.0 & 8.2693 & 7.30 & 6.4595 \\
\hline
\end{tabular}

(a) condition: $\bar{u}=10 \mathrm{~m} / \mathrm{sec}$

The magnitude of velocity change for 30-yr recurrence computed from Equation (25), including climatological data, is shown in Table 3. The conditions for obtaining these results are the same as in Table 2, except in those cases where the distribution of climatological mean wind speed was included. Comparing the results in Table 3 to the results in Table 2 indicates that the magnitude of velocity change with regard to the cases including the climatological data is significantly larger by a factor of more than five than those cases excluding the climatological wind data. 
TABLE 3. Velocity Change for 30-yr Recurrence, $\mathrm{m} / \mathrm{sec}$

\begin{tabular}{|c|c|c|c|}
\hline \multirow[b]{2}{*}{$\tau, \sec$} & \multicolumn{3}{|c|}{ Diameter of Wind Turbine, $m$} \\
\hline & Sma11, $1 \mathrm{~m}$ & Medium, $10 \mathrm{~m}$ & Large, $60 \mathrm{~m}$ \\
\hline 0.05 & 6.464 & 5.868 & 3.920 \\
\hline 0.1 & 8.925 & 8.357 & 7.196 \\
\hline 0.3 & 14.717 & 13.779 & 12.583 \\
\hline 0.5 & 18.379 & 17.241 & 16.126 \\
\hline 1.0 & 24.34 & 22.846 & 21.791 \\
\hline 3.0 & 34.603 & 31.773 & 30.916 \\
\hline 5.0 & 38.274 & 35.405 & 34.289 \\
\hline 10.0 & 40.762 & 38.536 & 36.631 \\
\hline
\end{tabular}

The magnitude of velocity change for a 30-yr recurrence with cutout speed of $25 \mathrm{~m} / \mathrm{sec}$ is shown in Table 4 . The results indicate that the magnitude of velocity change is substantially reduced.

TABLE 4. Velocity Change for 30-yr Recurrence with Cutout Speed of $25 \mathrm{~m} / \mathrm{sec}$

\begin{tabular}{lcccc} 
& \multicolumn{2}{c}{ Diameter of Wind Turbine, $\tilde{u}$ at $10 \mathrm{~m} / \mathrm{sec}$} \\
$\tau$, sec & Smal1, $1 \mathrm{~m}$ & Medium, $10 \mathrm{~m}$ & Large, $60 \mathrm{~m}$ \\
0.05 & 3.54 & 3.25 & 2.99 \\
0.1 & 4.91 & 4.65 & 4.26 \\
0.3 & 8.33 & 8.87 & 7.49 \\
0.5 & 10.58 & 10.17 & 9.64 \\
1.0 & 14.42 & 13.36 & 13.38 \\
3.0 & 22.04 & 21.20 & 20.47 \\
5.0 & 25.59 & 24.62 & 23.82 \\
10.0 & 29.08 & 27.97 & 27.02
\end{tabular}




\section{VARIATION OF GUST RISES WITH A NONDIMENSIONAL PARAMETER}

If Dryden's spectra are used for obtaining the standard deviation of velocity change $\left(\sigma_{\Delta u}\right)$, then, following Rice's theory and Equation (1), the number of crossings with gust amplitude difference exceeding a given level of $\Delta u$ per unit of time becomes:

$$
N=N_{0} e^{-a x^{2}}
$$

where

$$
\begin{aligned}
& x=\frac{\Delta u}{\sigma_{u}} \\
& a=\frac{1}{4\left(1-e^{-T}\right)} \\
& T=\frac{\bar{u} \tau}{L_{u}(z)}
\end{aligned}
$$

The theoretical results as shown in Equation (30) indicate that the exceedance parameter $(a)$ is dependent on the mean wind speed $(\bar{u})$, the turbulence scale $L_{u}(z)$ and the lag time $(\tau)$. 


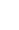




\section{REFERENCES}

Barr, N. M., D. Gangsaas and R. Schaeffer. 1974. Wind Models for Flight Simulator Certification of Landing and Approach Guidance and Control Systems. FAA-RD-74-206, U.S. Department of Transportation.

Counihan, J. 1975. "Adiabatic Atmospheric Boundary Layers: A Review and Analysis of the Data from the Period 1880-1972." Atmospher ic Environment, 9:871-905.

Davenport, A. G. 1961. "The Spectrum of Horizontal Gustiness Near the Ground in High Winds." Quarterly Journal Review of the Meteorological Society, 42:548-554.

Kaimal, J. C. 1973. "Turbulence Spectra Length Scales and Structure Parameters in Stable Surface Layer." Boundary-Layer Meteorology, $4: 289-309$.

Kaimal, J. C., J. C. Wyngaard, Y. I. Izumi and 0. R. Cote. 1972. "Spectral Characteristics of Surface-Layer Turbulence." Quarterly Journal Review of the Meteorological Society, 98:563-589.

Luers, J. K. 1973. A Model of Wind Shear and Turbulence in the Surface Boundary Layer. NASA-CR-2288, prepared for NASA by The University of Dayton Research Institute, Dayton, Ohio.

Ramsde11, J. V. 1975. Wind Turbulence Information for Vertical and Short Take-off and Landing (V/STOL) Operations in Built-Up Urban Areas Results of Meteorological Survey. FAA-RD-75-94, U.S. Department of Transportation.

Rice, S. 0. 1944. "Mathematical Analys is of Random Noise." Bell System Technical Journal, 23:282-332.

Rice, S. 0. 1945. "Mathematical Analys is of Random Noise." Bell System Technical Journal, 24:46-156.

Shellard, H. C. 1968. "Resu7ts of Some Recent Special Measurements in the United Kingdom Relevant to Wind Loading Problems." In Proceedings of International Symposium on Wind Effects on Buildings and Structures. Ottawa, Canada: Univ. of Toronto Press.

Teunissen, H. W. 1970. "Characteristics of the Mean Wind and Turbulence in the Planetary Boundary Layer." UTIAS Review. No. 32. 


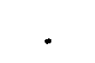


PNL -2530

UC -60

DISTRIBUTION

No. of

Copies

A. A. Churm

DOE Chicago Patent Group

9800 S. Cass Avenue

Argonne, IL 60439

C. I. Aspliden

Department of Energy

600 E Street, N.W.

Washington, DC 20545

G. P. Tennyson

Raytheon Service Company

141 C Wyoming Boulevard, NE

Albuquerque, NM 87123

27 DOE Technical Information Center

5 G. H. Fichtl

3706 College Park Circle

Huntsvill, AL 35805

\section{ONSITE}

2 DOE Richland Operations Office

P.0. Box 550

Richland, WA 99352

H. E. Ransom

R. K. Stewart
No. of

Copies

62 Pacific Northwest Laboratory

Battelle Boulevard

Richland, WA 99352

W. R. Barchet

R. L. Conley

J. R. Connel1

J. C. Doran

R. L. Drake

C. E. Elderkin

D. L. Elliott

T. R. Hiester

P. R. Partch (30)

W. T. Pennel $]$

E. H. Phinney

D. C. Powe11

J. V. Ramsdell

D. S. Renne

D. N. Reyes

H. L. Wegley

L. L. Wendell (5)

R. K. Woodruff

Technical Information - Library (5)

Publishing Coordination (2) 
